An Evaluation of the Effects of Valve Body Erosion on Motor-Operated Valve Operability

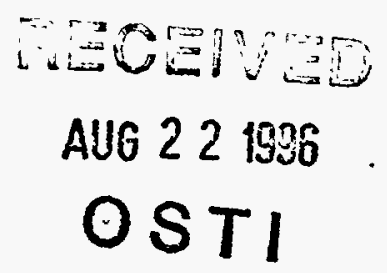

Thomas H. Hunt

Michael E. Nitzel

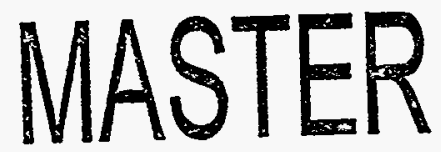

DISTRABUTION OF THLS DOCUMENT IS UNLMTED $R$ 
INEL-95/0648, Rev. 1

(formerly EGG-SSRE-10039 Rev. 0)

\section{An Evaluation of the Effects of Valve Body Erosion on Motor-Operated Valve Operability}

Thomas H. Hunt

Michael E. Nitzel

NRC Technical Monitor

G. H. Weidenhamer

Published December 1995

\section{Idaho National Engineering Laboratory Lockheed Martin Idaho Technologies Idaho Falls, Idaho 83415}

Prepared for the Division of Engineering Office of Nuclear Reactor Research U.S. Nuclear Regulatory Commission Washington, D.C. 20555 Under DOE Idaho Operations Office Contract DE-AC07-94ID 13223 Job Code: A6389 



\section{DISCLAIMER}

This report was prepared as an account of work sponsored by an agency of the United States Government. Neither the United States Government nor any agency thereof, nor any of their employees, makes any warranty, express or implied, or assumes any legal liability or responsibility for the accuracy, completeness, or usefulness of any information, apparatus, product, or process disclosed, or represents that its use would not infringe privately owned rights. Reference herein to any specific commercial product, process, or service by trade name, trademark, manufacturer, or otherwise does not necessarily constitute or imply its endorsement, recommendation, or favoring by the United States Government or any agency thereof. The views and opinions of authors expressed herein do not necessarily state or reflect those of the United States Government or any agency thereof. 


\section{DISCLAIMER}

Portions of this document may be illegible in electronic image products. Images are produced from the best available original document. 


\begin{abstract}
Engineers at the Idaho National Engineering Laboratory evaluated the effects of erosion-induced valve wall thinning on motor-operated valve operability. The authors reviewed reports that identified the extent and location of erosion damage in nuclear plant valves and chose a globe valve with severe erosion damage to assess the potential for loss of operability. They developed a finite element model of the selected valve and performed structural analyses with valve closing forces, seismic effects, and increased erosion areas to analyze the effects of the erosion on structural integrity. The results indicate that while some local stresses at the points of maximum erosion exceeded yield, the general stresses were well below yield. Therefore, the displacements will be small and bending will not occur. The authors concluded that erosion-related wall thinning is not likely to create an operability problem for motor-operated valves.
\end{abstract}

Job Code: A6389-Aging-Components and Systems IV

iii 


\section{EXECUTIVE SUMMARY}

Wall thinning from erosion has caused damage in valves typical of those installed in a variety of systems in nuclear power plants. The available damage reports indicate that among safety-related systems, residual heat removal (RHR) systems appear to have the highest incidence of damage from erosion. Service water systems seem to incur a high incidence of erosion-related damage in nonsafety systems.

When extensive erosion does occur, excessive localized or distributed wall thinning is possible, which could create undue stresses and deformations in the valve body. These deformations could lead to relative displacements, which may in turn induce disc or stem binding. Binding would prevent the valve from performing its safety or control function.

Because of these concerns, the NRC commissioned the Idaho National Engineering Laboratory (INEL) tò evaluate the effects of erosion-induced valve wall thinning on motor-operated valve (MOV) operability. This investigation was sponsored as part of the NRC's Nuclear Plant Aging Research (NPAR) program. The evaluation consisted of the following elements:

- Reviewing reports that identify the extent and location of erosion damage in nuclear plant valves

- Choosing a specific valve where severe damage was occurring

- Developing a finite-element model of the valve

- Performing a structural analysis of the valve with valve closing forces and seismic effects after reducing the valve's wall thicknesses to simulate the eroded conditions

- Analyzing the results of the structural analyses.

This report only evaluates the effect of erosion-related wall thinning on MOV operability. This limits the investigation to damage occurring to the valve itself. It excludes any damage that may occur downstream in the connected piping as a result of flow perturbations occurring in the valve. While this damage would affect the operability of the system, it does not directly affect the operability of the valve and therefore is not part of this study.

As the first step in our study, we reviewed existing reports and failure events to identify where erosion damage is occurring in valves, and the extent and severity of the damage. Appendix A summarizes a representative selection of these reports. This review revealed that valves in the RHR system in boiling water reactors (BWRs) are among those most likely to experience erosion. It also indicated that a globe valve that is frequently throttled would be most affected. Therefore, we chose a 16-in. carbon steel globe valve used in the RHR suppression pool test line as a typical valve. The chosen valve had experienced the most severe damage reported for the RHR system.

Our next step was to perform a finite element analysis of this valve. The model developed represents the complete valve body, seat, and bonnet regions of the valve, including the areas where erosion had been observed. Since the selected valve is normally closed or nearly closed, the model 
included full system pressure (225 psig maximum pump dead head pressure) upstream of the valve seat. Because of the normal operating configuration of the valve, no internal pressure was modeled downstream of the valve seat. Normal operating temperature of $150^{\circ} \mathrm{F}$ was accounted for in the model's material properties. Conservative estimates of the valve stem force required to seat the valve were also modeled. The maximum moments on the valve caused by the attached piping and the seismic effects of the eccentric valve operator were also included as loads on the valve.

As part of the analysis, we made three "scoping" analysis computer runs simulating degraded valve body conditions. These computer runs simulated valve erosion damage worse than that which would be expected to occur. The first run was a conservative model of the erosion that was observed on the Brunswick valve (see Appendix B). The second run simulated through-wall erosion that would leak and be detected. The third run used even larger overall erosion areas to simulate erosion growth. The results of these analysis runs were evaluated and some local stresses above yield were found. The stress levels decreased rapidly with distance from the areas of maximum erosion. Based on this observation, we concluded that erosion-related wall thinning would not be likely to create an operability problem for MOVs. 


\section{CONTENTS}

ABSTRACT $\ldots \ldots \ldots \ldots \ldots \ldots \ldots \ldots \ldots \ldots \ldots \ldots \ldots \ldots \ldots \ldots \ldots \ldots$ iii

EXECUTIVE SUMMARY $\ldots \ldots \ldots \ldots \ldots \ldots \ldots \ldots \ldots \ldots \ldots \ldots \ldots$ v

INTRODUCTION $\ldots \ldots \ldots \ldots \ldots \ldots \ldots \ldots \ldots \ldots \ldots \ldots \ldots \ldots \ldots$

EROSION PROBLEMS IN THE NUCLEAR INDUSTRY $\ldots \ldots \ldots \ldots \ldots \ldots \ldots$

FINITE ELEMENT MODEL $\ldots \ldots \ldots \ldots \ldots \ldots \ldots \ldots \ldots \ldots \ldots \ldots \ldots$

STRUCTURAL ANALYSIS $\ldots \ldots \ldots \ldots \ldots \ldots \ldots \ldots \ldots \ldots \ldots \ldots \ldots$

CONCLUSIONS $\ldots \ldots \ldots \ldots \ldots \ldots \ldots \ldots \ldots \ldots \ldots \ldots \ldots \ldots \ldots \ldots \ldots \ldots \ldots \ldots \ldots$

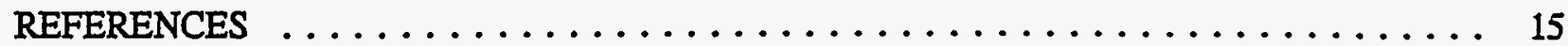

Appendix A-Summaries of Erosion Damage Reports $\ldots \ldots \ldots \ldots \ldots \ldots \ldots \ldots$ A-1

Appendix B-Brunswick Event Description $\ldots \ldots \ldots \ldots \ldots \ldots \ldots \ldots \ldots \ldots$ B-1

Appendix C-Analysis of a 16-Inch Globe Valve with Eroded Walls-

Description of the Finite Element Model Development ............... C-1

Appendix D-Analysis of a 16-Inch Globe Valve with Eroded Walls-

Description of the Analysis Results . . . . . . . . . . . . . . . D 1

\section{FIGURES}

1. Cross-sectional and overhead views of Anchor-Darling 16-in. globe valve $\ldots \ldots \ldots \ldots 5$

2. Wire-frame drawing of model of 16 -in. globe valve $\ldots \ldots \ldots \ldots \ldots \ldots \ldots$

3. Stress contour plot of the bonnet cylinder region of 16 -in. globe valve $\ldots \ldots \ldots \ldots \ldots$

4. Stress contour plot of the highest stressed region in the 16 -in. globe valve-third

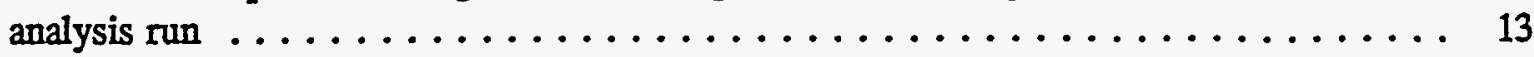

C-1. Simplified view of $16-$ in. globe valve and erosion areas $\ldots \ldots \ldots \ldots \ldots \ldots \ldots$

C-2. I-DEAS finite element model of 16 -in. globe valve with eroded walls $\ldots \ldots \ldots \ldots$ C-5

C-3. Bonnet region elements with the areas of maximum erosion ofr 16-in. globe valve model $\ldots \ldots \ldots \ldots \ldots \ldots \ldots \ldots \ldots \ldots \ldots \ldots \ldots \ldots \ldots \ldots \ldots \ldots$ 
D-1. Representative stress contour plot of eroded bonnet region $\ldots \ldots \ldots \ldots \ldots$

\section{TABLES}

1. Percent of throttleable valves larger than 4 in. in RHR systems of BWRs and PWRs . . . 3

2. Maximum stress results with $t_{\min }=0.10$ in $\ldots \ldots \ldots \ldots \ldots \ldots$

3. Maximum stress results with $t_{\min }=0.010$ in $\ldots \ldots \ldots \ldots \ldots \ldots$

4. Maximum stress results with increased erosion area (third computer run) . . . . . . 12

D-1. Maximum stress results with $t_{\min }=0.10$ in $\ldots \ldots \ldots \ldots \ldots \ldots \ldots$

D-2. Maximum stress results with $t_{\min }=0.010$ in $\ldots \ldots \ldots \ldots \ldots \ldots$

D-3. Maximum stress results with increased erosion area (third computer run) . . . . . . D-9 


\section{An Evaluation of the Effects of Valve Body Erosion on Motor-Operated Valve Operability}

\section{INTRODUCTION}

Since 1983, the U.S. Nuclear Regulatory Commission (NRC) has issued information notices, bulletins, technical reports, and a generic letter addressing nuclear plant problems related to erosion damage to pumps, piping, and valves (see the Reference section). Erosion in nuclear plant systems continues to be a concern to the NRC.

Wall thinning from erosion has caused damage in valves typical of those installed in a variety of systems in nuclear power plants. The available damage reports indicate that among safety-related systems, residual heat removal (RHR) systems appear to have the highest incidence of damage from erosion. Service water systems seem to incur a high incidence of erosion-related damage in nonsafety systems.

When extensive erosion does occur, excessive localized or distributed wall thinning is possible, which could create undue stresses and deformations in the valve body. These deformations could lead to relative displacements, which may in turn induce disc or stem binding. Binding would prevent the valve from performing its safety or control function.

Because of these concerns, the NRC commissioned the Idaho National Engineering Laboratory (INEL) to evaluate the effects of erosion-induced valve wall thinning on motor-operated valve (MOV) operability. This investigation was sponsored as part of the NRC's Nuclear Plant Aging Research (NPAR) program. The evaluation consisted of the following elements:

- Reviewing reports that identify the extent and location of erosion damage in nuclear plant valves

- Choosing a specific valve where severe damage was occurring

- Developing a finite-element model of the valve

- Reducing the valve's wall thicknesses to simulate the eroded conditions and then performing a structural analysis of the valve with valve closing forces and seismic effects

- Analyzing the results of the structural analyses.

The results of the latest analyses varied from those previously obtained for two reasons. First, the inertial effects of the seismic acceleration of the valve operator's eccentric mass was not included; second, the later analyses used a later version of the analysis computer code with a somewhat different solution technique. The results indicate that some stresses were above yield; however, these areas were highly local and confined to the immediate area of the maximum erosion damage.' With 
these exceptions, stress levels were below yield and it was judged that an operability problem did not exist.

This report was first issued in May 1993. This revision was completed to incorporate the seismic effects of the eccentric mass of the valve operator and to investigate how increased erosion areas would affect the stress distributions in the valve walls. It should also be noted that stress results for load cases that do not include seismic loads differ somewhat from those previously reported. This is because a later version of the I-DEAS computer code was used for the current analyses and an improved plate element solution technique is included in the current version of the code.

This report only evaluates how erosion-related wall thinning affects MOV operability. This limits the investigation to damage occurring to the valve itself. It excludes any damage that may occur downstream in the connected piping as a result of flow perturbations occurring in the valve. While this damage would affect the operability of the system, it does not directly affect the operability of the valve and therefore is not part of this study.

As the first step in our study, we reviewed existing reports and failure events to identify where erosion damage is occurring in valves, and the extent and severity of the damage. ${ }^{1-11,2}$ Appendix A summarizes a representative selection of these reports. This review revealed that valves in the RHR systems of boiling water reactors (BWRs) are among those most likely to experience erosion. It also indicated that a globe valve that is frequently throttled would be most affected. Therefore, we chose a 16-in. carbon steel globe valve used in the RHR suppression pool test line as a typical valve. The chosen valve had experienced the most severe damage reported for the RHR system. Details of the finite element and structural analyses are given in subsequent sections of this report.

\section{EROSION PROBLEMS IN THE NUCLEAR INDUSTRY}

Most of the erosion-related problems in the nuclear industry have occurred in piping and valves. In the case of valves, the erosion damage usually results in internal leakage past the seating surfaces. All of the catastrophic failures have occurred in nonsafety system piping, primarily the main turbine extraction steam and the main feedwater systems. Service water systems also have experienced a large number of erosion-related failures, including through-wall leakage.

In the first-line safety systems, primarily emergency coolant injection and containment isolation systems, few occurrences of through-wall erosion damage are reported. However, there have been examples of valve body damage caused by erosion. One of the more significant instances occurred at the Brunswick Nuclear Plant. In 1989, evidence of severe erosion damage was discovered during normal maintenance activities on the Unit 1 RHR inboard low-pressure coolant injection (LPCI) valve. An investigation on the redundant LPCI train valve indicated that it, too, had suffered severe damage. The investigation determined the cause to be cavitation-induced erosion because of throttled flow through the valve. An expanded investigation revealed four more valves in the RHR systems and one valve in the high-pressure coolant injection (HPCI) system also had suffered cavitation-induced erosion damage. Additional details of this incident are provide in Appendix B.

a. Private communication with D. Casada, Oak Ridge National Laboratory, Oak Ridge, Tennessee, 1991. 
The cavitation-induced erosion damage in valves prompted the NRC to initiate a study by Oak Ridge National Laboratory (ORNL). This study reviewed industry experience with erosion damage and determined that the service water and condensate/feedwater systems accounted for $78 \%$ of the reported through-wall valve failures. Their report did not identify any through-wall failures in first-line safety systems, a fact they attributed to the lower operating hours for these systems. To perform a more detailed study on erosion, ORNL studied a single system in depth. ORNL chose the RHR systems at both BWRs and pressurized water reactors (PWRs) for three reasons: (a) they are critical safety systems, (b) the previously mentioned Brunswick event occurred in the RHR system, and (c) they are operated more often than other first-line standby safety systems.

Throttleable valves greater than 4 in. nominal size were considered to be of primary importance. The review of RHR systems identified approximately 900 throttleable valves larger than 4 in. in the RHR systems of BWRs and PWRs; nearly 500 of these were located in carbon steel piping systems in BWRs. Table 1 shows the distribution of the valves identified. ORNL's review showed that BWRs

Table 1. Percent of throttleable valves larger than 4 in. in RHR systems of BWRs and PWRs.

Percent of

Valve type valve population ${ }^{2}$

Babcock \& Wilcox Plants

Stainless steel butterfly

0.5

Stainiess steel globe $\quad \underline{2.6}$

Total

3.1

Combustion Engineering Plants

Stainless steel butterfly

Stainless steel globe

$\underline{11.2}$

Total

16.6

General Electric Plants

Stainless steel globe

5.2

Carbon steel globe

47.4

Carbon steel butterfly

3.1

Total

55.7

Westinghouse Plants

Stainless steel globe

0.2

Stainless steel butterfly

0.5

Carbon steel globe

18.8

Carbon steel butterfly

4.8

Total

24.3

a. Total valve population is approximately 925 valves. Percentages are the fraction of all valves. 
account for the majority of the valves larger than 4 in. used in RHR systems, and the number of globe valves in BWR RHR systems is larger than the total number of valves used in all of the PWR RHR systems.

Our primary purpose in reviewing the ORNL study and other operating history was to determine an appropriate valve to be modeled in this study. Although erosion appears to be most prevalent in the service water and feedwater systems, neither of these systems tends to have valves that are subjected to high stresses during accident conditions. In concurrence with ORNL's reasons for detailed study of RHR systems, we elected to model an RHR valve. Also, because the ORNL study showed that more valves exist in BWR RHR systems, and most of these are globe valves, we chose to model a carbon steel globe valve typical of one used in BWRs. The Brunswick event provided detailed descriptions of actual erosion damage and the locations of the damage. Consequently, we chose to model the Anchor-Darling ${ }^{b}$ 16-in. globe valve used in the suppression pool test line at Brunswick. Figure 1 shows simple cross-sectional and overhead views of this valve.

The locations where the erosion damage occurred are illustrated by the shaded areas in Figure 1. These areas ranged from about 1 to $5 \mathrm{in}^{2}$. The original thickness of these areas was about 1.25 in. thick. The actual damage removed nearly $1 \mathrm{in}$. of material thickness in some areas. The damage was severe enough to reduce the wall thickness to less than the required code thickness for a $300-1 \mathrm{~b}$ valve, and an engineering analysis was required to justify continued operation following the outage without repair or replacement of the valve.

\section{FINITE ELEMENT MODEL}

A primary concern for this study was that erosion damage could occur without detection until the valve failed in service. Unless the bridge structure (the part of the valve body that encloses the seat ring of the valve) or valve body experienced through-wall erosion, the damage would not be detected during normal operation. This occurred at the Brunswick plant, where the damage was found when the valve was disassembled for routine maintenance. No prior indication of the damage had been apparent. If the fluid cavitation had continued to erode the valve body, the valve may not have retained adequate structural integrity to operate when required.

To evaluate this problem, we modeled the valve using the I-DEAS modeling and analysis software. A wire frame drawing of the model is shown in Figure 2. The intent of the model is to bound the stresses that the valve would experience and to determine whether the valve material yield stresses would be exceeded. To do this, we decided it was necessary only to perform an elastic analysis. If the results showed elastic stresses were not exceeded or were exceeded only in local areas, the strain would be in the elastic range, displacements would be small, and valve operability most likely would not be inhibited. If the results showed elastic stress values were exceeded over large areas, additional analysis may be needed to study the effect of valve wall thinning on MOV operability.

b. Mention of specific products and/or manufacturers in this document implies neither endorsement or preference, nor disapproval by the U.S. Government, any of its agencies, or Lockheed Idaho Technologies of the use of a specific product for any purpose. 


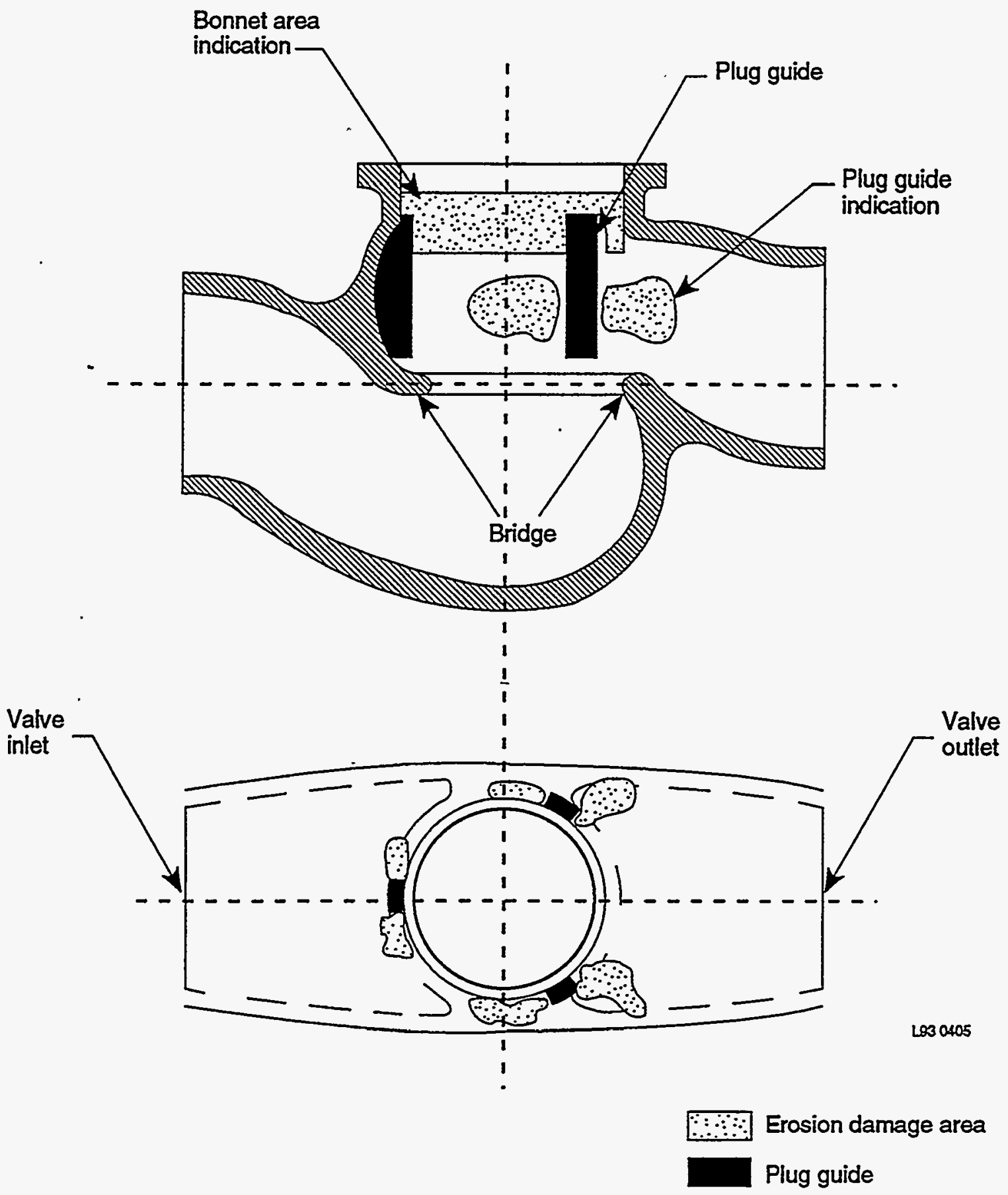

Figure 1. Cross-sectional and overhead views of Anchor-Darling 16-in. globe valve. 


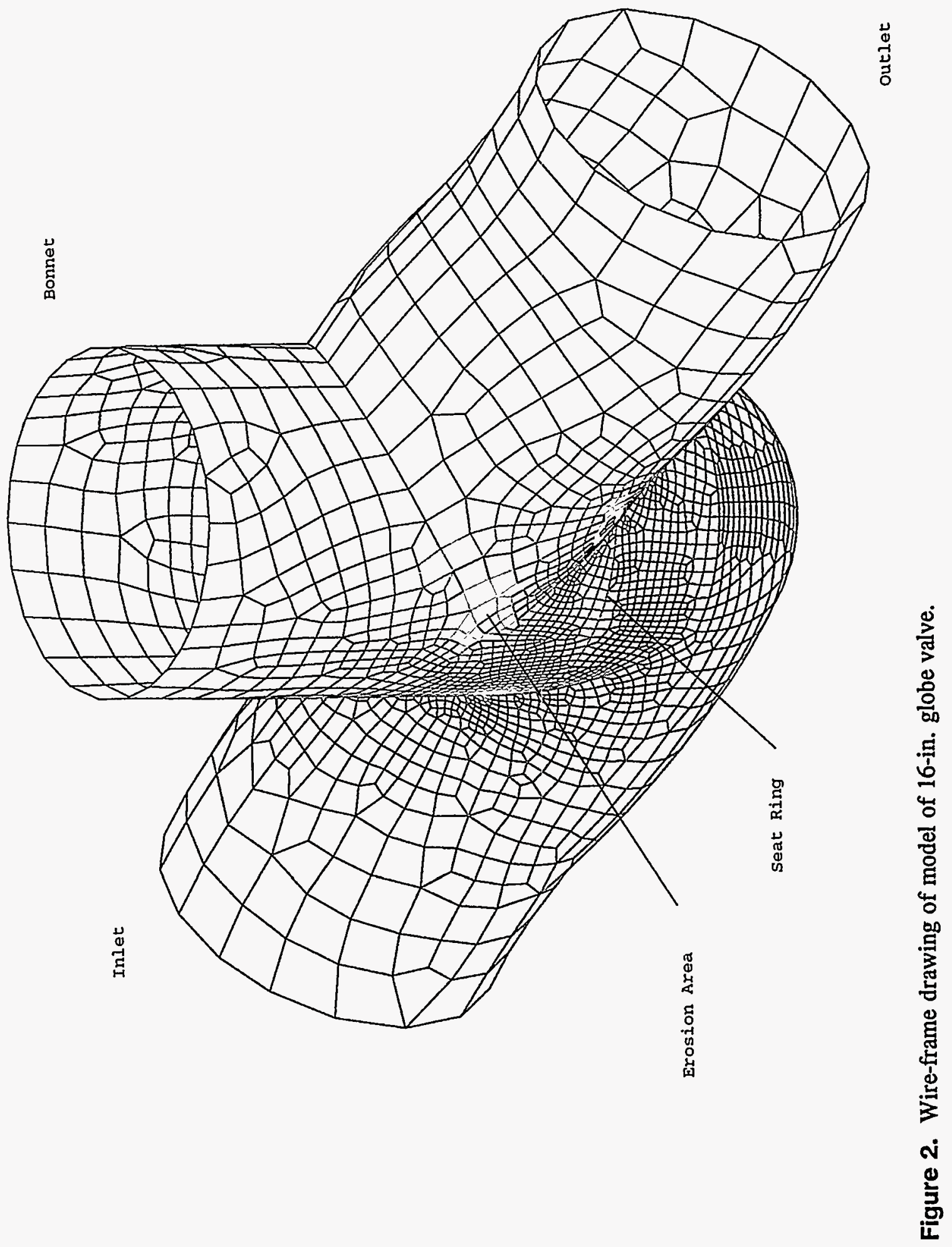


Using the Brunswick event as a template for modeling erosion damage, we duplicated the seven areas of damage in our model. The areas of greatest damage occurred downstream of the seating surfaces in the valve body on each side of the three plug guides. The seventh location was in the bonnet cylinder area. This last area had only minor uniform damage, which covered almost the entire circumference of the upper region of the bonnet cylinder.

The damaged areas around the guides in the Brunswick valve varied from about 1 to 5 in. ${ }^{2}$ with losses of about $0.375-0.75$ in. of wall thickness. The eroded areas tapered down in thickness from the nominal wall thickness $(\approx 1.25 \mathrm{in}$.) to the minimum value that remained $(0.5-0.875 \mathrm{in}$.). In the finite element model, the minimum wall thickness was decreased to $0.10 \mathrm{in}$. for the first run and 0.010 in. for the second and third runs. The surface area of erosion included in the first computer run closely represented the eroded surface areas observed in the Brunswick valve. The erosion areas were enlarged slightly in the second run to allow smoother transitions in wall thickness. The erosion areas (what Brunswick termed "indications $1-6^{\text {") }}$ ) were considerably enlarged for the third run to investigate-the effects of increased erosion. Since the original thickness of the walls was greater than 1.25 in., the minimum values chosen for the analysis were conservative representations of the maximum thinning observed. This allowed us to reasonably simulate conditions for a through-wall leak while maintaining the numerical stability of the model. Also, Brunswick personnel performed an engineering analysis to determine the minimum allowable wall thickness for the valve at operating pressure (about $195 \mathrm{psig}$ ), which is 0.492 in. Since the minimum wall thickness values chosen for the finite element analyses were well below 0.492 in., we believe that the results of the analyses would provide conservative indications of any structural deficiencies under the loading conditions considered.

The valve was modeled in the closed position, with internal pressure only upstream of the seat ring. The individual loads that were included in each run were the piping forces and moments on the valve ends, plug/seat forces and their reaction forces on the upper bonnet, normal operating pressure, pump dead head pressure, and the seismic inertia effects produced by the eccentric mass of the valve operator. The seismic loads for the valve operator were conservatively taken to be higher (by about $67 \%$ ) than those required by the plant's valve specifications. The appropriate combinations of these loads were then used to calculate the stress levels in the valve model. The selected loading combinations provided the maximum load across the seat for a conservative structural analysis.

Because there is no pressure load downstream of the seat, the locally thinned elements did not have direct pressure stress. This is a local effect, however, and would not affect the overall ability of the valve body to resist the deformations required to produce binding of the plug or stem and failure of the valve. Since the eroded areas in the upper bonnet cylinder had only minor uniform damage, we duplicated this area in the model without any modification or increase in its severity. Appendix C describes the model and modeling assumptions in detail.

\section{STRUCTURAL ANALYSIS}

The I-DEAS software was used to develop the globe valve model and perform the stress analyses. Details of the model and the load combinations considered in the model are identified in Appendix D. After completing the stress calculations, we made stress contour plots. Figure 3 shows a representative bottom surface stress contour plot resulting from the analysis of the valve with a minimum eroded wall thickness of 0.010 in. Using the color scale in Figure 3, one can see that the 
RESULTS: $15-$ B.C. 0 , LOAD 12 , STRESS_15

STRESS - VON MISES MIN: 6.55E+02 MAX: $4.80 E+04$

VALUE ORTION : ACTUAL

FRAME OF REF : PART SHELL SURFACE: BOTTOM
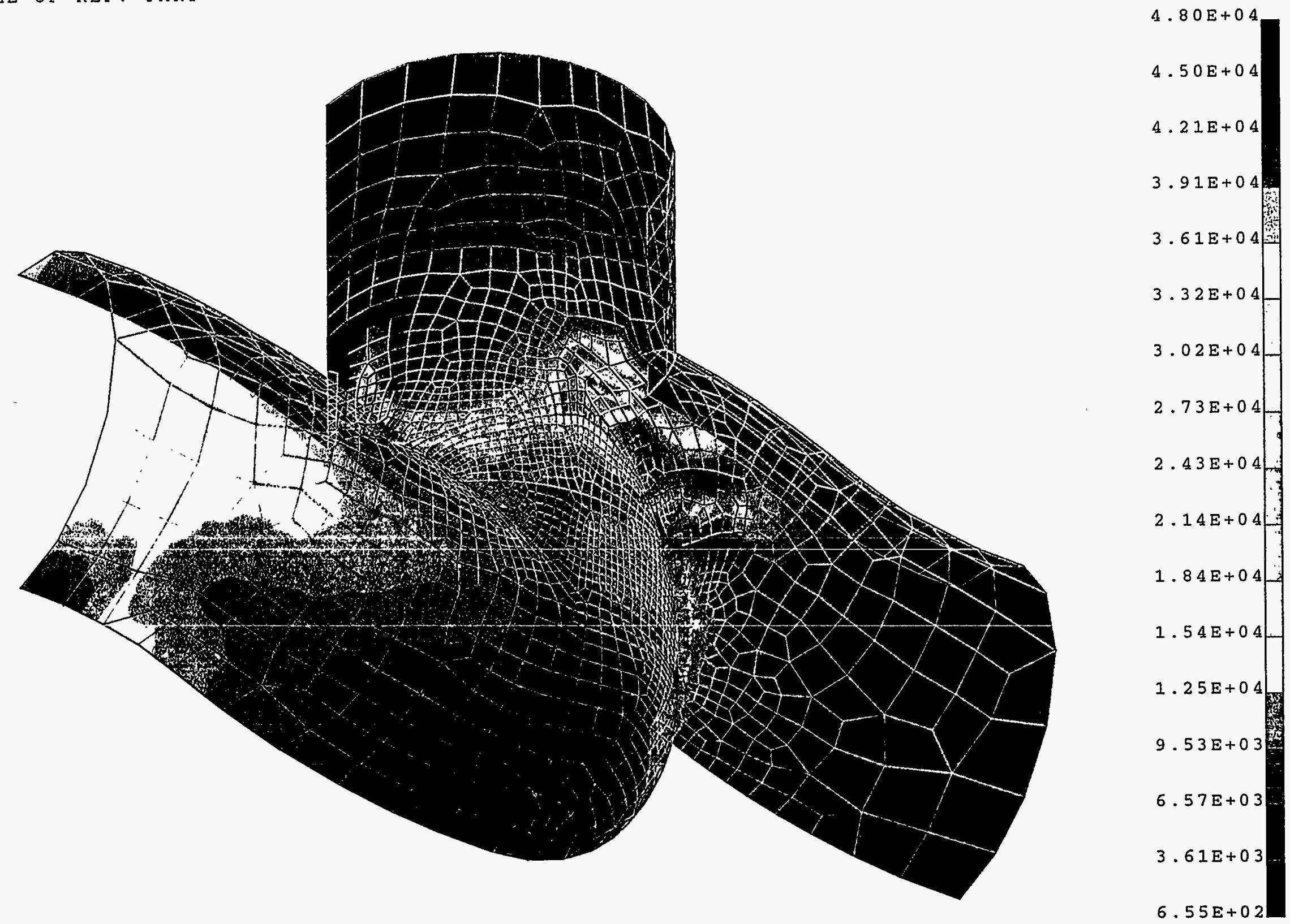

Figure 3. Stress contour plot of the bonnet cylinder region of -16 -in. globe valve. 
highest stresses are occurring approximately in the middle of the figure. These high stresses are located in the outlet regions of the valve near the plug guides. For the run where the minimum wall thickness was 0.10 in., the stress contour plot would appear similar to that shown in Figure 3 but with lower stresses. The stress contour plot for the third run, which included larger erosion areas, would appear similar to Figure 3, only with slightly larger areas of higher stresses. The maximum stresses for all three cases are listed in Tables 2, 3, and 4. A detailed description of the analysis results is given in Appendix D.

The analytical results show that the stresses are above the yield stress for some load combinations. As shown in Tables 2, 3, and 4, the yield stress for the valve material is $34.4 \mathrm{ksi}$ at an operating temperature of $150^{\circ} \mathrm{F}$. The maximum stress indicated in Table 2 is approximately $20 \%$ above the yield stress. As expected, the maximum stress for the second run is higher. The minimum wall thickness for the second run was 0.010 in., and the results shown in Table 3 are approximately $40 \%$ above the yield value at the maximum stress location. The maximum stress $(84.1 \mathrm{ksi})$ for the third run is a factor of 2.45 times the yield stress allowable value. However, examination of the results from the third run clearly show that this stress is a local peak stress in the area of the minimum wall thickness $(0.010$ in.) element. A stress contour plot of results obtained in the critical section of the model for the third run is shown in Figure 4. The results in Figure 4 show that the stresses rapidly decrease with distance from the minimum thickness element and that the lower level of the general area stresses would be expected to control the structural response of the valve.

By evaluating the results and contour plots of Figures 3 and 4, we can see that the stresses exceeded yield only in local areas. The stresses above yield occurred at maximum erosion areas (designated as indications 2 and 5 in Figure C-3) in the first two runs and at and near the maximum erosion area in the third run. The stress magnitudes decreased rapidly with distance from these two locations. Thus, the overall response of the valve was controlled by the stresses below the yield point and an elastic analysis is adequate for our analysis. Also, the deflections that might contribute to binding of the valve are small and are controlled by the valve's overall behavior. Therefore, binding of the valve is not likely to occur.

One of our initial concerns was that the erosion damage observed at Brunswick that occurred on the bridge area could lead to loss of support for the seat ring. Although this area was modeled with much greater than observed damage, the bridge has a large margin to yield.

\section{CONCLUSIONS}

The analysis described above is not a complete analytical treatment of the valve. The objective of this analysis was to conduct a scoping study that would indicate the structural margin that may be available when wall thinning is encountered similar to what was observed at Brunswick. This information could then be used to predict how the erosion might affect MOV operability.

The results of our analyses show that even with conservative modeling of the erosion and the seismic loading, the stresses in the model valve were below the yield stress for the material except in local areas at the locations of maximum erosion damage. Because the response of the valve is controlled by elastic stresses and the deflections are small, an elastic analysis is adequate for the purposes of this scoping analysis. Therefore, we conclude that erosion-related wall thinning is not likely to create an operability problem for MOVs. 
Table 2. Maximum stress results with $t_{\min }=0.10$ in.

Calculated Von Mises stressest

(ksi)

\begin{tabular}{|c|c|c|c|c|c|c|c|c|}
\hline Model area & $\begin{array}{l}\text { Element } \\
\text { surface }\end{array}$ & $\begin{array}{c}\text { Load } \\
\text { combination } 1^{b}\end{array}$ & $\begin{array}{c}\text { Load } \\
\text { combination } 2^{b}\end{array}$ & $\begin{array}{c}\text { Load } \\
\text { combination } 3\end{array}$ & $\begin{array}{c}\text { Load } \\
\text { combination } 4\end{array}$ & $\begin{array}{c}\text { Load } \\
\text { combination } 5\end{array}$ & $\begin{array}{c}\text { Load } \\
\text { combination } 6\end{array}$ & $\begin{array}{l}\text { Yield stress } \\
\text { (ksi) }\end{array}$ \\
\hline \multirow[t]{3}{*}{ Seat ring } & Top & 10.0 & 10.2 & 11.9 & 10.6 & 12.1 & 10.8 & 34.4 \\
\hline & Middle & 10.9 & 11.2 & 12.6 & 11.5 & 12.9 & 11.8 & 34.4 \\
\hline & Bottom & 11.8 & 12.3 & 13.5 & 12.4 & 13.9 & 13.0 & 34.4 \\
\hline
\end{tabular}

Bridges

$\begin{array}{lrr}\text { Top } & 13.6 & 14.0 \\ \text { Middle } & 4.3 & 3.3 \\ \text { Boltom } & 9.0 & 8.7\end{array}$

○ Upper bonnet
(Area 7)

\begin{tabular}{|c|c|c|c|c|c|c|c|}
\hline Top & 6.7 & 6.8 & 7.3 & 4.7 & 7.4 & 4.8 & 34.4 \\
\hline Middle & 3.4 & 3.3 & 4.3 & 3.6 & 4.3 & 3.6 & 34.4 \\
\hline Bottom & 4.8 & 4.8 & 5.5 & 4.6 & 5.4 & 4.6 & 34.4 \\
\hline
\end{tabular}

$\begin{array}{lllll}\text { Bonnet cylinder } & \text { Top } & 26.8 & 26.6 & 30.4 \\ \text { (Areas 1-6) } & \text { Middle } & 28.5 & 28.2 & 32.2 \\ & \text { Bottom } & 36.3 & 36.1 & 41.2 \\ & & & \\ \text { a. } \quad \text { Load combinations are } & & \\ 1=\text { Operating pressure + seat force + piping end moments } \\ 2=\text { Pump dead head pressure + seat forec + piping end moments } \\ 3=\text { Operating pressure + seat force + piping end moments + X direction operator inertia } \\ 4=\text { Operating pressure + seat force + piping end moments + } \mathrm{Z} \text { direction operator inertia } \\ 5=\text { Pump dead head pressure + seat force + piping end moments + X direction operator inertia } \\ 6=\text { Pump dead head pressure + seat force + piping end moments + Z direction operator inertia. }\end{array}$

b. Load combinations 1 and 2 are the "original" load cases reported in May 1993. The results for these cases vary from those previously reported because

a. The I-DEAS solution techniques for thin shell elements changed between versions 6.0 and Master Series 1.3c.

b. Piping end moments and operator inertia moments were applied as nodal forces instead of using constraint elements. 
Table 3. Maximum stress results with $t_{\min }=0.010$ in.

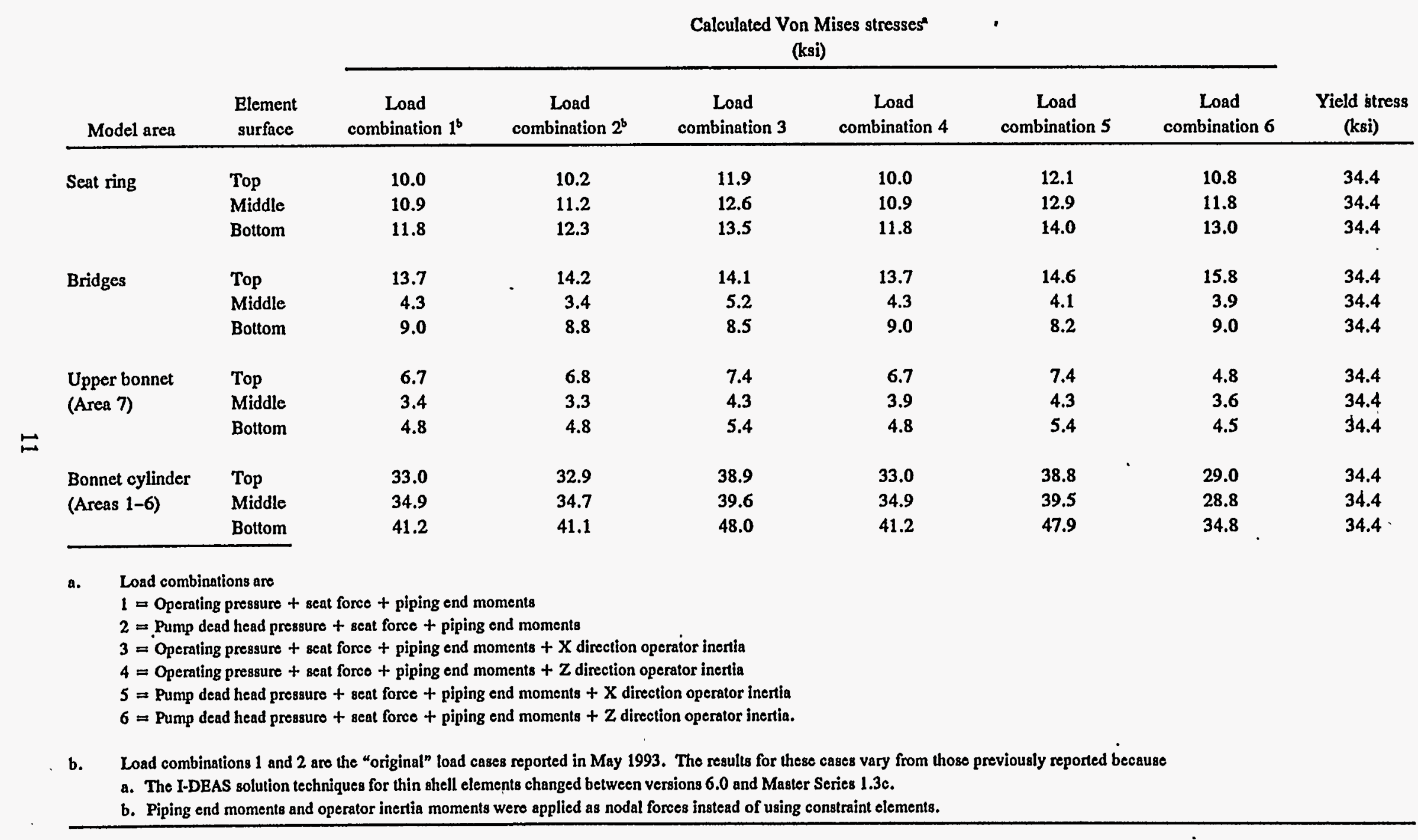


Table 4. Maximum stress results with increased erosion area (third computer run).

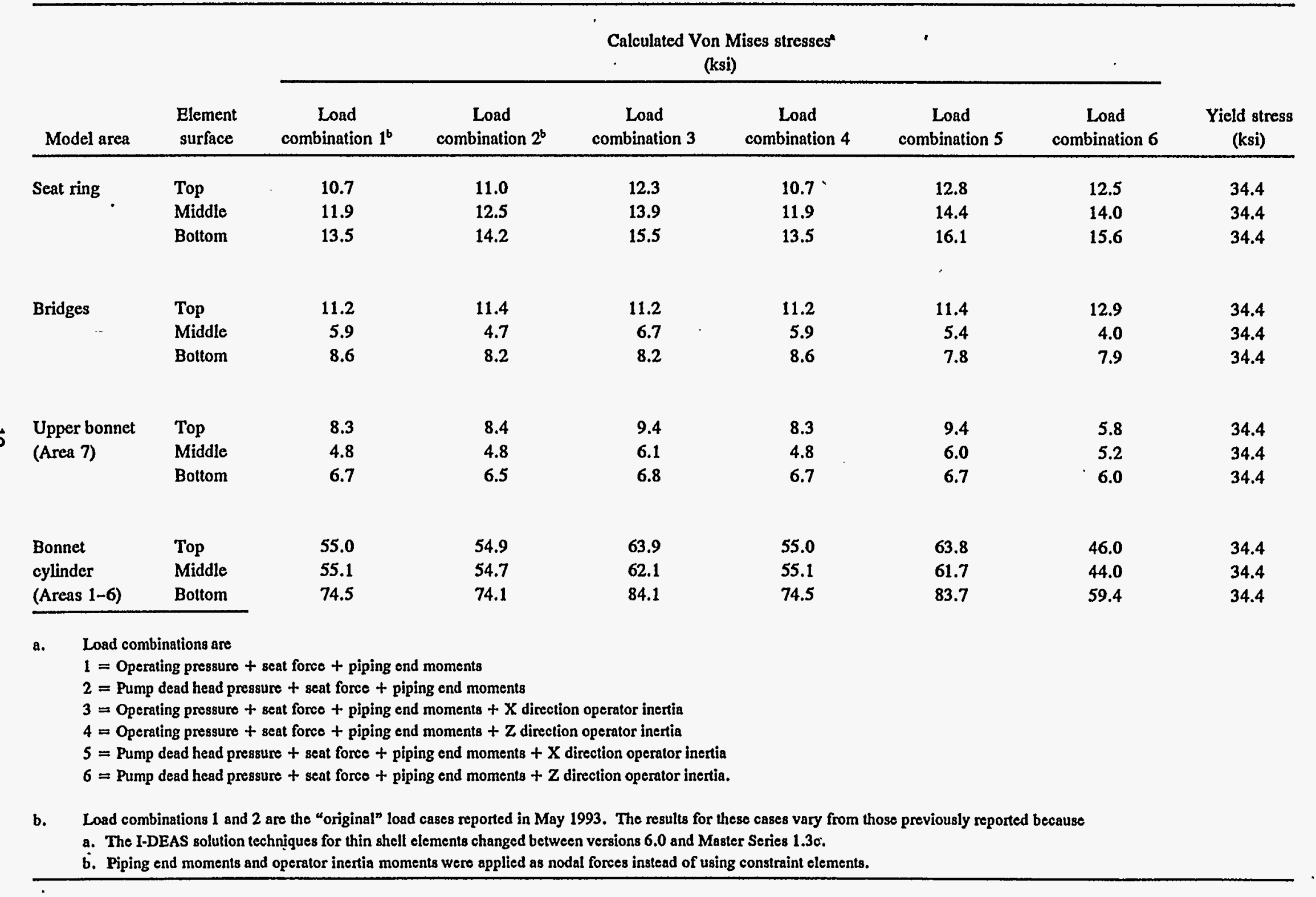




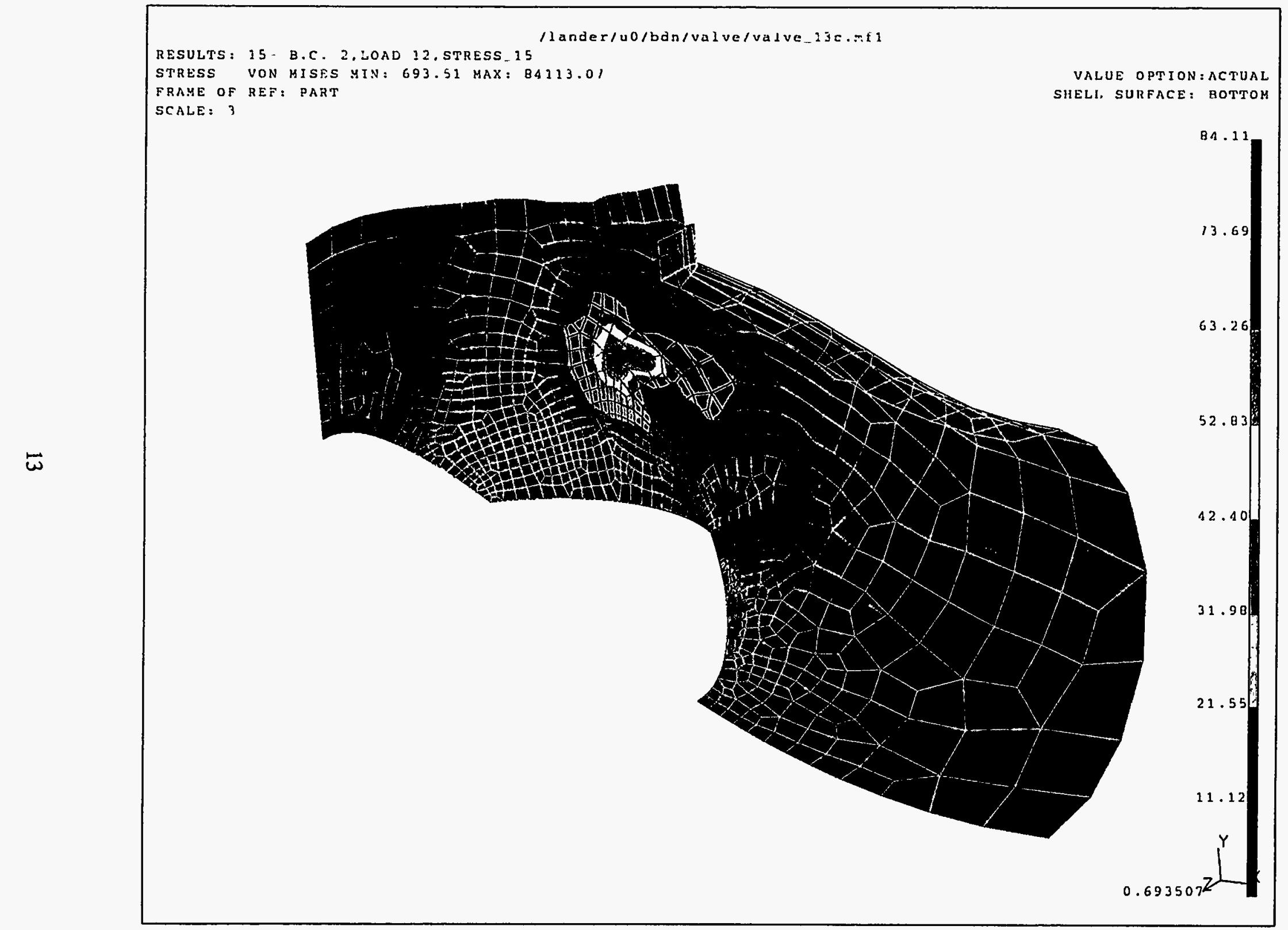

Figure 4. Stress contour plot of the highest stressed region in the 16-in. globe valve-third analysis run. 



\section{REFERENCES}

1. NRC, Service Water System Problems Affecting Safety-Related Equipment, Generic Letter 89-13, Supplement 1, April 4, 1990.

2. NRC, Service Water System Problems Affecting Safety-Related Equipment, Generic Letter 89-13, July 18, 1989.

3. NRC, Excessive Valve Body Erosion at Brunswick, AEOD/E908, September 29, 1989.

4. NRC, Summary of January 11, 1989 Meeting Held with BWR Owner's Group Regarding Valve Degradation By Erosion, January 31, 1989.

5. NRC, Valve Body Erosion, NRC Information Notice 89-01, January 4, 1989.

6. NRC, Pump Damage Caused by Low Low-flow Operation, IE Information Notice 89-08, January 26, 1989.

7. NRC, Summary of January 10, 1989 Meeting Held With CP\&L Regarding Valve Degradation by Erosion, January 31, 1989.

8. NRC, Potential Safety-Related Pump Loss, NRC Bulletin 88-04, May 5, 1988.

9. NRC, Thinning of Pipe Walls in Nuclear Power Plants, NRC Bulletin 87-01, July 9, 1987.

10. NRC, Erosion in Nuclear Power Plants, AEOD/E416, June 11, 1984.

11. NRC, Misapplication of Valves by Throttling Beyond Design Range, IE Information Notice 83-55, August 22, 1983. 


\section{Appendix A}

\section{Summaries of Erosion Damage Reports}




\section{Appendix A}

\section{Summaries of Erosion Damage Reports}

\section{OFFICE OF ANALYSIS AND EVALUATION OF OPERATIONAL DATA (AEOD)}

The AEOD sponsored several reports reviewing and investigating instances of erosion-related problems occurring in the commercial nuclear industry. These reports investigated trends in erosion-related failures and evaluated industry responses and the programs intended to resolve these problems.

NRC, Erosion in Nuclear Power Plants, AEOD/E416, June 11, 1984.

This report documents problems with erosion-related failures in both steam and water piping systems. It identifies areas having potential safety impact and suggests review of six areas: service water systems, J-tubes in steam generators, emergency feedwater systems, erosion-related leakage of main steam isolation valves, potential for rupturing steam lines, and personnel safety.

NRC, Excessive Valve Body Erosion at Brunswick, AEOD/E908, September 29, 1989.

This report discusses the valve erosion damage at Brunswick Unit 1. Several groups of erosion-related failures are identified that may have a potential impact on nuclear safety. These include failures from cavitation-induced damage, vibration damage to valve assemblies and piping supports, piping erosion downstream of throttled valves, severe degradation of pumps, low-flow damage to pumps, and erosion fouling of heat exchangers.

\section{Office of Nuclear Reactor Regulation (NRR).}

NRR issued two bulletins in 1987 and 1988 that addressed concerns about erosion-related degradation of piping systems and pumps.

NRC, Thinning of Pipe Walls in Nuclear Power Plants, Bulletin No. 87-01, July 9, 1987.

This bulletin addresses the problems associated with erosion-corrosion failures in carbon steel piping systems. Large-diameter piping systems previously were not routinely monitored for erosion-corrosion damage because of the limited number of failures that have occurred in carbon steel piping systems. The bulletin requires all licensees to provide information on their programs to monitor piping wall thicknesses in carbon steel piping systems.

NRC, Potential Safety-Related Pump Loss, Bulletin No. 88-04, May 5, 1988.

This bulletin discusses the problems associated with inadequate minimum flow protection for safety-related centrifugal pumps. As flow is decreased for an operating pump, cavitation and other 
problems may occur that could damage the pump. "This low-flow condition allows the fluid in the pump to begin to cavitate, causing vibration and damage to the impeller and pump casing. 


\section{Appendix B}

\section{Brunswick Event Description}




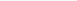




\section{Appendix B}

\section{Brunswick Event Description}

In December of 1988, Brunswick Unit 1 technicians conducted maintenance on the stem and backseat of the residual heat removal (RHR) system's low-pressure coolant injection (LPCD) valve, 1-E11-F017B (a 16-in. carbon steel angle body globe valve). When the valve was disassembled, localized pockets of erosion damage were noted in the walls of the valve body just above the seat ring on the outlet volute of the valve. Follow-up inspection of these pockets determined that more than half (2.3 in. of the original 3.5-4 in.) of the wall thickness had eroded away. This reduced the wall thickness below the minimum required by the appropriate design code [American National Standards Institute (ANSI) 16.5]. The redundant RHR subsystem LPCI valve, 1-E11-F017A, was then inspected and similar indications were noted in this valve, although the minimum wall thickness requirements were met.

During this same period, the RHR suppression pool cooling inboard isolation valve, 1-E11-F024B, failed a local leak rate test, and was disassembled for repair and inspection. The inspection noted areas of localized erosion damage in the walls of the valve body and on the bridge supporting the seat. These indications were above the seat ring and adjacent to the plug guides. In one location, the wall thickness did not meet the minimum required. The redundant RHR subsystem suppression pool cooling inboard isolation valve, 1-E11-F024A, was then disassembled for inspection. Similar indications were noted, but the wall thicknesses did not fall below the minimum values.

Following the discovery of the problems on the Unit 1 RHR valves, 29 valves in the RHR, core spray, reactor core isolation cooling, and high-pressure coolant injection (HPCD) system were inspected. Only one other valve had indications of erosion damage, the HPCI full flow test throttle valve (1-E41-F008). The damage to 1-E41-F008 was limited to eroded plug guides, with only minor damage to the valve walls.

The Unit 2 RHR LPCI injection and suppression pool cooling inboard isolation valves (2-E11-F017A/B and 2-E11-F024A/B) also were inspected. These inspections revealed similar areas damaged to a lesser extent than the Unit 1 valves.

The root cause of the erosion damage was throttling flow through the valves. This throttling caused cavitation and resulted in the localized erosion of the valve. The investigation also showed that the cavitation occurred at all flow rates for the suppression pool cooling inboard isolation valves and became more prevalent at higher flow rates. The LPCI injection valves also cavitated at all flow rates, but the cavitation increased at the lower flow rates. 


\section{Appendix C}

\section{Analysis of a 16-Inch Globe Valve with Eroded Walls- \\ Description of the Finite Element \\ Model Development}





\section{Appendix C}

\section{Analysis of a 16-Inch Globe Valve with Eroded Walls- Description of the Finite Element Model Development}

\section{MODEL DESCRIPTION}

\section{Valve Description}

The intent of this analysis is to perform a "scoping analysis" to gauge the effect of erosion on the valve and to determine whether more detailed analysis is warranted. It is not intended to be a detailed stress analysis that considers every possible load case.

The analyzed valve is a 16-in. nominal size globe valve with an American National Standards Institute (ANSD) 300-lb class rating manufactured from A216, grade WCB, cast carbon steel. The component was manufactured by Anchor-Darling Industries ${ }^{2}$ and is representative of several that are installed in the residual heat removal (RHR) piping systems of both nuclear power generating units at the Brunswick plant. A simplified view of the valve and a plan view of some of the erosion areas are shown in Figure C-1. The valve was originally qualified for operation under the ANSI B31.1 Power Piping code, 1973 Edition (hereinafter referred to as "the Code") and the ANSI B16.5 Standard, "Steel Pipe Flanges and Flanged Fittings."

\section{Modeling Assumptions}

No engineering or casting drawings were available for use in constructing the model of the 16-in. globe valve. Consequently, we used field measurements and sketches obtained from Brunswick plant personnel and Anchor-Darling personnel during the model development. In some cases, assumed values were used where no other information was available. Also, since this is a scoping analysis, certain simplifying assumptions were appropriate. Major model features and simplifying assumptions employed in this analysis are discussed in the paragraphs below.

The model was developed using the I-DEAS software package written by the Structural Dynamics Research Corporation. This software includes drafting, solid modeling, analysis, and post processing capabilities. Interfaces to other widely used analysis codes (e.g., ABAQUS) are also included within I-DEAS. The solid modeling feature of the code was used to construct a representation of the complete valve, which contained 5,026 nodes and 4,992 quadrilateral plate elements. The finite element model is shown in its entirety in Figure C-2. For clarity, a view of

a. Mention of specific products and/or manufacturers in this document implies neither endorsement or preference, nor disapproval by the U.S. Government, any of its agencies, or Lockheed Martin Idaho Technologies of the use of a specific product for any purpose. 

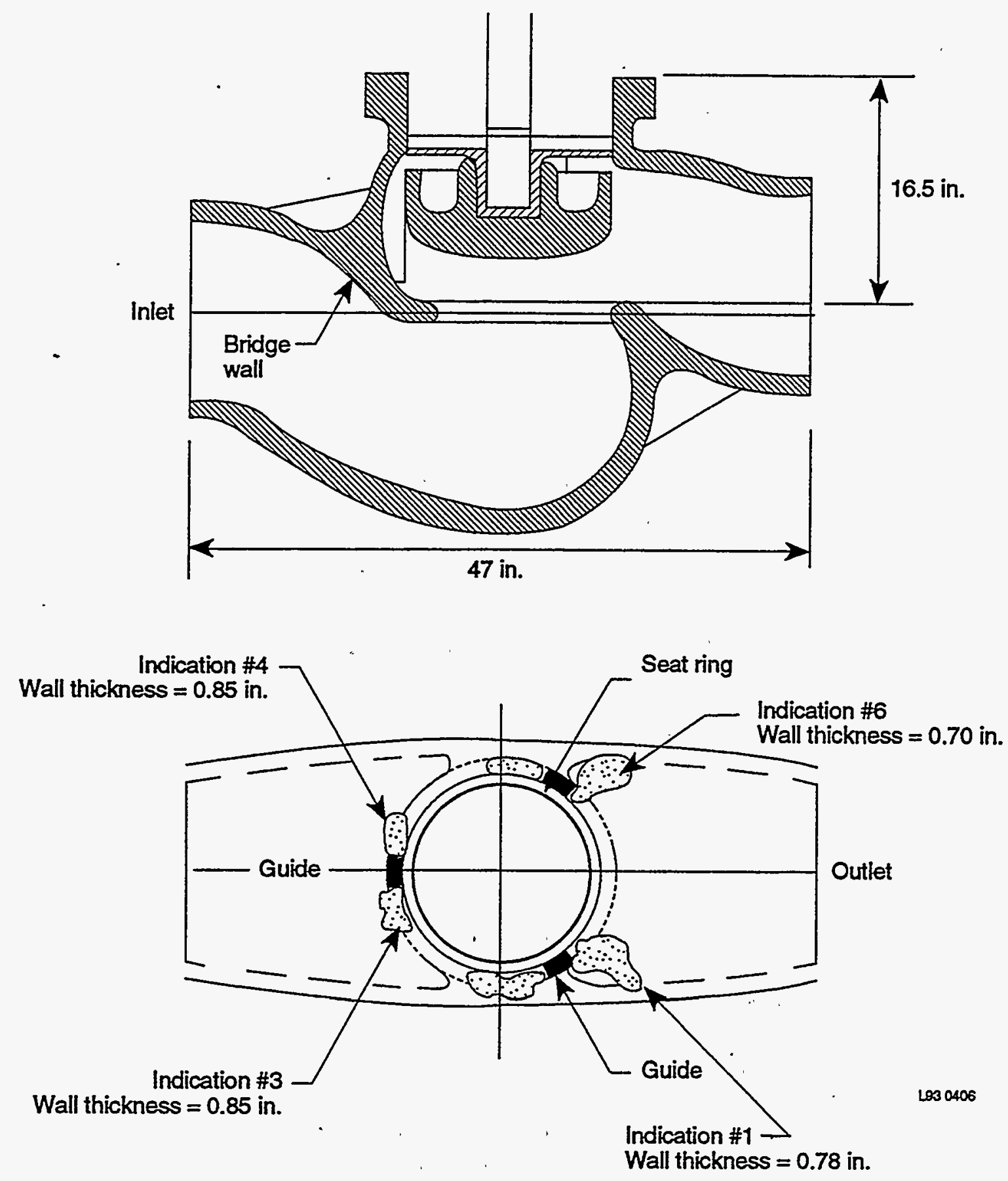

Figure C-1. Simplified view of $16-$ in. globe valve and erosion areas. 


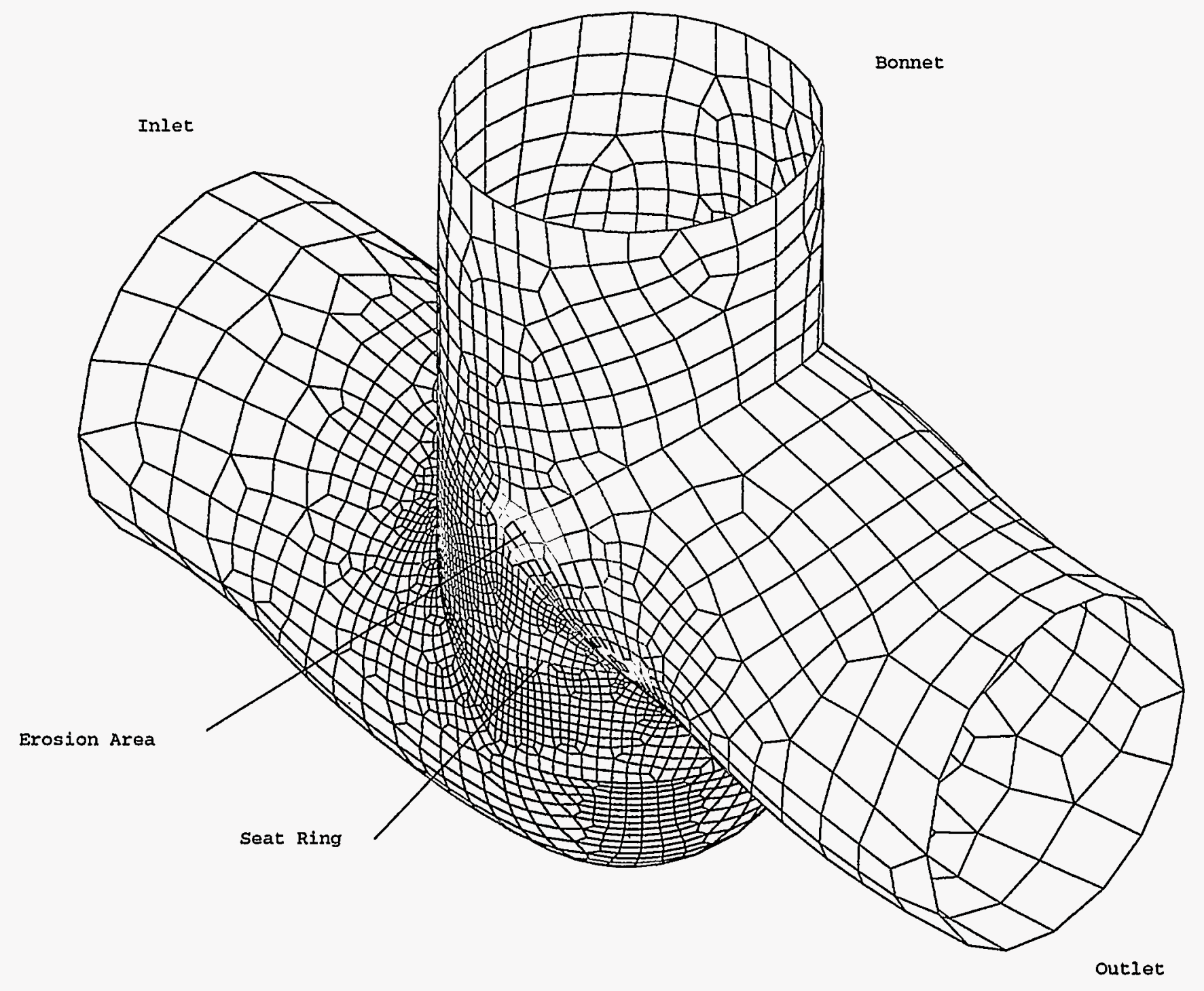

Figure C-2. I-DEAS finite element model of 16 -in. globe valve with eroded walls. 
only the bonnet region elements, including the areas of maximum erosion (noted as indications 1-6), is shown in Figure C-3.

The inlet, outlet, and bonnet sections of the valve were modeled with circular cross sections.

The actual physical dimensions of these sections changed somewhat at different locations on the valve, but exact dimensions were not available at all locations. Based on analytical experience, this simplifying assumption was deemed appropriate to the overall goal of the analysis effort.

A second simplification was the omission of the valve plug guides. These guides are located on the bonnet cylinder side walls and function to guide the plug in its vertical travel during operation and provide lateral restraint for the plug. The guides would have a stiffening effect on the valve walls in their vicinity. Because of the curved surfaces blending the guides to the walls, no significant additional stress would be expected in these areas. Thus, omission of the guides will tend to make the results err on the conservative side because the deflections, and thus the stresses, that are calculated will be somewhat larger than what would actually occur. Appendix D discusses the analysis procedure and results in greater detail.

\section{Operating Conditions and Imposed Loads}

The following temperature and pressure conditions were used for the 16-in. globe valve:

$$
\begin{array}{ll}
\mathrm{P}_{\mathrm{D}}=\text { design pressure } & =375 \mathrm{psig} \\
\mathrm{P}_{\mathrm{op}}=\text { normal operating pressure } & =160 \mathrm{psig} \\
\mathrm{T}_{\mathrm{D}}=\text { design temperature } & =225^{\circ} \mathrm{F} \\
\mathrm{T}_{\mathrm{op}}=\text { normal operating temperature } & =150^{\circ} \mathrm{F}
\end{array}
$$

Note that $160 \mathrm{psig}$ is the normal operating discharge pressure while the rated discharge pressure is 195 psig.

In actual operation, the valve would be subjected to a variety of thermal conditions, internal pressures, and piping system structural loads. For the purposes of this scoping analysis, however, we wanted to limit the number of loads that were considered. For this reason, the load cases considered were limited to the following combinations:

$$
\begin{aligned}
& P_{\text {op }}+F_{\text {reat }}+M_{\text {pipe }} \\
& P_{\text {pdi }}+F_{\text {zeat }}+M_{\text {pipo }} \\
& P_{\text {op }}+F_{\text {seat }}+M_{\text {pipe }}+M_{\text {osx }} \\
& P_{\text {op }}+F_{\text {zeat }}+M_{\text {pip }}+M_{\infty z} \\
& P_{\text {pdh }}+F_{\text {ecat }}+M_{\text {pipe }}+M_{\text {oxx }}
\end{aligned}
$$




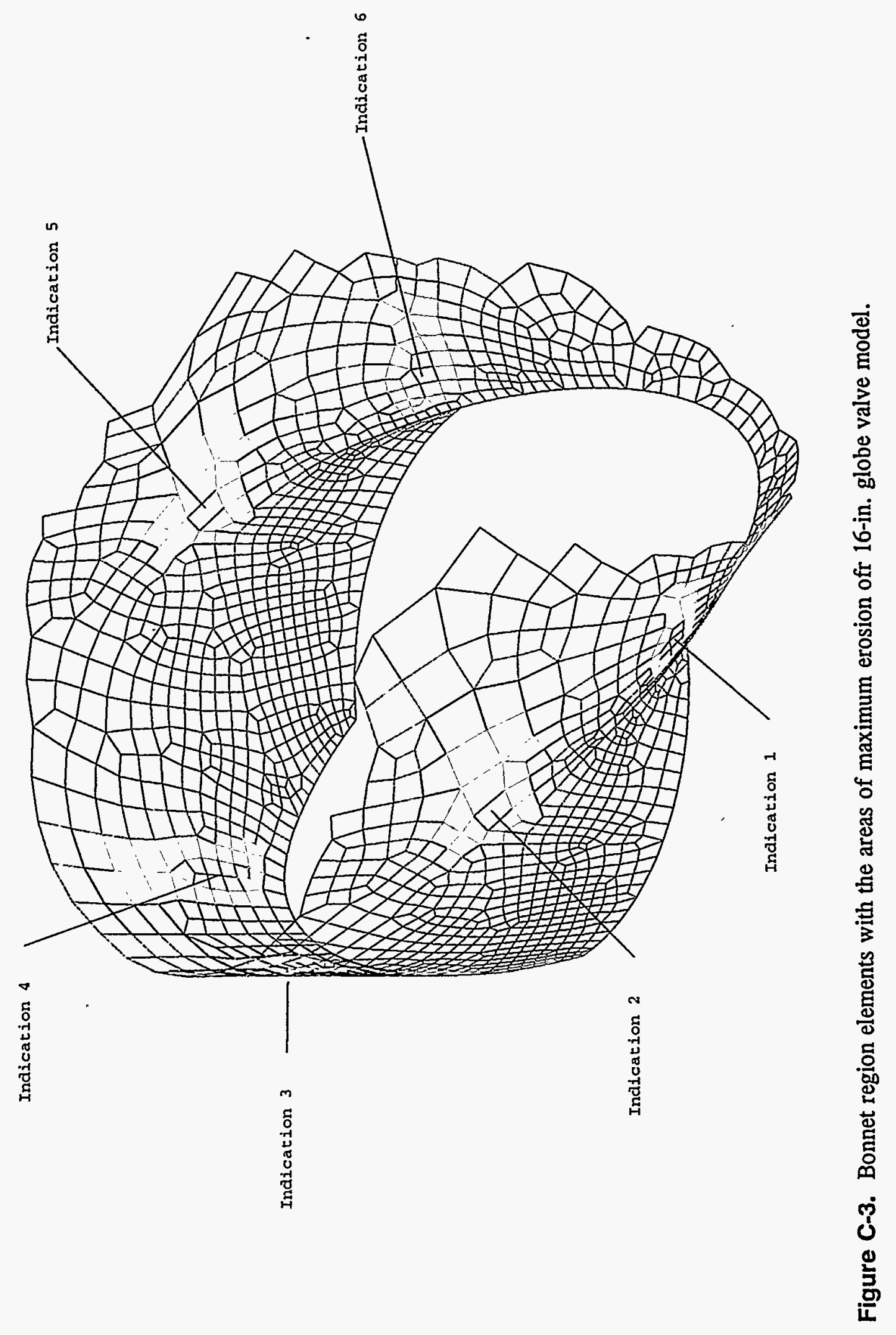


$P_{\text {pdh }}+F_{\text {eed }}+M_{\text {pipe }}+M_{o c e}$

where

$$
\begin{aligned}
& F_{\text {sat }}=\text { valve plug seating force }(\mathrm{lb}) \\
& \mathrm{M}_{\text {oxx }}=\text { operator seismic moment about model global } \mathrm{x} \text { axis (in.-lb) } \\
& \mathrm{M}_{\text {ox }}=\text { operator seismic moment about model global } \mathrm{z} \text { axis (in.-lb) } \\
& \mathrm{M}_{\text {pioc }}=\text { piping system moments at the valve weld ends (in.-lb) } \\
& \mathrm{P}_{\text {pdh }}=\text { pump dead head pressure (psig). }
\end{aligned}
$$

Brunsiwick plant personnel provided the necessary pressures and seat force information and a table of piping system moments for various thermal, weight, and seismic conditions. A valve operator acceleration of $5 \mathrm{~g}$ was selected to conservatively represent the $3 \mathrm{~g}$ level that was used for valve qualification by the utility. The piping system moments were examined and a worst case combination of weight, thermal, and seismic moments was constructed to conservatively represent the structural loads applied by the piping system. The resulting loads were

$$
\begin{aligned}
\mathrm{P}_{\mathrm{op}} & =160 \mathrm{psig} \\
\mathrm{P}_{\mathrm{pdh}} & =225 \mathrm{psig} \\
\mathrm{F}_{\text {scat }} & =92,464 \mathrm{lb} \\
\mathrm{M}_{\text {oax }} & =\mathrm{M}_{\mathrm{ocz}}=192,000 \text { (in.-lb) } \\
\mathrm{M}_{\text {pie }} & =-58,824 \mathrm{in} \cdot-1 \mathrm{~b} \text { (about the x global axis) } \\
& =-48,504 \mathrm{in} \cdot-1 \mathrm{~b} \text { (about the y global axis) } \\
& =229,392 \mathrm{in} \cdot-1 \mathrm{~b} \text { (about the z global axis). }
\end{aligned}
$$

\section{Material Properties}

The valve was manufactured using A216, grade WCB, cast carbon steel. This material has a maximum carbon content of $0.30 \%$ and an ultimate tensile strength of $70.0 \mathrm{ksi}$. Table A-1 in the ANSI B31.1 Code lists a maximum allowable stress of $14.0 \mathrm{ksi}$ in the operating temperature range of -20 to $650^{\circ} \mathrm{F}$. Interpolation of data contained in Table $\mathrm{C}-1$ in the Code indicated a Young's modulus of $27.78 \times 10^{6} \mathrm{psi}$ at the operating temperature of $150^{\circ} \mathrm{F}$. Similarly, interpolation of data from Table I-2.1 in Section III of the American Society of Mechanical Engineers (ASME) Code gives a yield stress of $34.4 \mathrm{ksi}$ at the operating temperature of $150^{\circ} \mathrm{F}$. 


\section{Load Application}

Throughout our analyses, the valve was assumed to be in the closed position. To represent this situation, internal pressure (either normal operating or pump dead head) was applied normal to the plate surfaces of the elements representing only that portion of the valve upstream of the seat. Pressure forces on the valve plug would normally be transmitted to the bonnet and this was represented with a vertical force on the bonnet top edge. Since the combination of piping bending moments, plug seating force applied to the seat ring, and the differential pressure across the bridge structure elements should produce the maximum stress condition, the closed valve assumption is considered to be a conservative approach to satisfying the analysis goals.

The seating force applied by the plug to the seat ring was applied as a line load around the inner circumference of the seat ring. Appropriate force components were used to simulate the actual direction of the seat force as it is applied to the ring. In the actual valve, the seat load reaction path is through the bonnet cylinder walls and bonnet flange. This load reaction was simulated by forces applied around the top of the bonnet cylinder.

The piping system moment loading was obtained from Brunswick plant personnel as described earlier. Moment loading by itself will produce a linear stress distribution varying from tension to compression on the pipe. The piping moments were converted to the equivalent nodal forces that would produce the same stress distribution, and the nodal forces were applied to the model at the valve-piping weld point. Similarly, the moments caused by the seismic motion of the operator were also applied to the top of the valve bonnet as nodal forces. Both sets of equivalent nodal forces were combined and applied to produce the most severe loading and stress results. This conservative method of application accounted for our lack of information about phasing of the seismic responses of the piping and valve operator and the actual sequence of load application. The nodal load sets representing the moment loads were combined with the internal pressure and seat force load cases in the loading combinations listed above. Results were obtained for each of the loading combinations for both computer runs.

\section{Boundary Conditions}

The model boundary conditions consisted of restraints on the upstream end of the valve nodes. The nodes in the plane of the weld end (upstream end of the valve) were restrained so that rigid body rotation could not occur and so that all applied loads would be reacted properly.

\section{Modeling of Eroded Areas}

Information received from Brunswick plant personnel indicated that seven general areas of erosion had been observed. In general, erosion occurred on the bonnet cylinder walls on both side of the three plug guides. These eroded areas varied in size from approximately 1 to $5 \mathrm{in}^{2}$. The vertical locations varied from 4 to $6 \mathrm{in}$. above the upper surface of the seat ring. The maximum erosion depths ranged from 0.375 to 0.75 in. deep. The original wall thickness in these areas was not available; however, it was assumed to be at least equal to the 1.25-in. thickness measured elsewhere. These conditions occurred in six of the erosion areas (termed Indication 1-6 in the Brunswick data). The eroded areas tapered down in thickness from the nominal wall thickness ( $\approx 1.25$ in.) to the 
minimum value that remained $(0.5-0.875 \mathrm{in}$.). This was simulated in the finite element model by beginning at the outside edge of an erosion area and "stepping down" the element plate thicknesses to the minimum value selected for the analysis. Thus, each erosion area was modeled with several groups of elements with different thicknesses to represent the transition into the minimum value of the eroded area. This technique not only provided reasonable representation of the actual erosion patterns but also helped to avoid the possibility of numerical instabilities that large relative differences in adjacent element properties might cause during solution of the finite element model.

For the first computer run, a wall thickness value of 0.10 in. was used as the minimum value for all six of the eroded areas described above. This value was used instead of the actual minimum thickness remaining because we wanted to investigate the effect that a minimum wall thickness condition would have on the stress levels. The Code calculation for minimum thickness is discussed in further detail in Appendix D. The second computer run used a wall thickness value of $0.010 \mathrm{in}$. as the minimum thickness to simulate thinning that might result in a through-wall leak. Also, the erosion areas were enlarged slightly for the second run, thus enabling the thicknesses to be stepped down in additional increments. Erosion areas ("indications") $1-6$ were considerably enlarged in overall size for the third run to investigate the effects of increased erosion. Since the original thickness of the walls was greater than 1.25 in., the minimum values chosen for the analysis were conservative representations of the maximum thinning observed. The elements representing the minimum thickness values remained the same for all three computer runs.

The seventh erosion area occurred in the upper region of the bonnet cylinder, beginning about $2 \mathrm{in}$. below the bonnet flange and extending vertically down near the tops of the plug guides. This erosion also extended around most of the circumference of the upper bonnet cylinder. The information received from the Brunswick plant personnel indicated that the erosion in this region was fairly uniform and had removed about 0.125 in. of the wall material thickness. This configuration was represented in the finite element model by simply reducing the thickness of the appropriate. elements in the bonnet cylinder by 0.125 in. (i.e., wall thickness equalled 1.125 in.) for computer runs one and two. An additional $0.125 \mathrm{in}$. of erosion was represented in the third computer run by reducing the wall thickness in this region to $1.0 \mathrm{in}$. 


\section{Appendix D}

\section{Analysis of a 16-Inch Globe Valve with Eroded Walls- \\ Description of the Analysis Results}




\section{Appendix D}

\section{Analysis of a 16-Inch Globe Valve with Eroded Walls- Description of the Analysis Results}

ANALYTICAL APPROACH

The intent of this analysis is to perform a "scoping analysis" to gage the effect of erosion on the valve and to determine whether more detailed analysis is warranted. It is not intended to be a detailed stress analysis that considers every possible load case.

As discussed in Appendix C, we developed the model using the I-DEAS software package written by the Structural Dynamics Research Corporation. ${ }^{2}$ This software includes drafting, solid modeling, finite element solution, and post processing capabilities. Interfaces to other widely used analysis codes (e.g., ABAQUS) are also included within I-DEAS. We used the solid modeling feature of the code to construct a representation of the complete valve that contained 5,026 nodes and 4,992 quadrilateral plate elements. The finite element model is shown in its entirety in Figure C-2. For clarity, a view of only the seat ring and bridge structure elements is shown in Figure C-3.

I-DEAS Version 6.0 was used for the original analysis and the newer I-DEAS Master Series Version $1.3 \mathrm{c}$ was used for the most recent computer runs. The I-DEAS code is installed on the Idaho National Engineering Laboratory's Applied Engineering and Development Laboratory (AEDL) Department's Scientific Computing computer system. This version of I-DEAS was subjected to the benchmark tests and quality control requirements required by the Structural Dynamics Research Corporation before release of the code. This version of the code also is currently undergoing benchmark testing by Applied Mechanics Group personnel. An Applied Mechanics Group Computer Program Configuration Documentation form for this version of I-DEAS and is available for reference if desired.

The globe valve normally would be subject to dynamic loads during some phases of actual operation. Experience has shown, however, that the dynamic response can be conservatively modeled with a static equivalent analysis. For this analysis, we selected linear elastic static analysis as sufficient to satisfy the requirements of a scoping analysis. Therefore, we used the linear static solution option within I-DEAS to calculate results discussed below.

a. Mention of specific products and/or manufacturers in this document implies neither endorsement or preference, nor disapproval by the U.S. Government, any of its agencies, or Lockheed Martin Idaho Technologies of the use of a specific product for any purpose. 


\section{MINIMUM WALL THICKNESS CONSIDERATIONS}

The 16-in. globe valve originally qualified for operation under the 1973 edition of the ANSI B31.1 Power Piping Code (hereafter referred to as "the Code") and the ANSI B16.5 Standard, "Steel Pipe Flanges and Flanged Fittings."

Equation (3) in Subparagraph 104.1.2 of the code can be used to calculate the recommended minimum wall thickness for components subject to internal pressure. This equation is

$$
t_{m}=\frac{P D_{0}}{2(S E+P y)}+A
$$

where

$$
\begin{aligned}
& \mathrm{P}=\text { design pressure (psig) } \\
& \mathrm{D}_{0}=\text { outside diameter (in.) } \\
& \mathrm{SE}=\text { maximum allowable stress due to internal pressure and joint efficiency (psi) } \\
& \mathrm{y} \cdot=\text { coefficient from Table 104.1.2.A of the Code ( } 0.40 \text { for this case) } \\
& \mathrm{A}=\text { additional thickness as defined in Subparagraph } 104.1 .2 \text { of the Code (in.). }
\end{aligned}
$$

When $A$ is assumed to equal zero, a minimum wall thickness of 0.212 in. is required by the Code to contain the design pressure of $375 \mathrm{psig}$. This calculation, based on Equation (D-1) (the equation for pipe components), was used as an approximation to choose a conservative value for the model. The minimum value, reported by Brunswick, was developed from valve design equations.

Based on the calculations described above, the finite element model in the first computer run used a value of $0.10 \mathrm{in}$. for those elements representing the areas of maximum erosion. This value allowed us to investigate the stress levels when the walls had eroded below the minimum thicknesses allowed by the Code. Since the object of this analysis was to determine whether severe erosion would be likely to impair the valve's operability, we considered this thickness value for the most highly eroded areas to be a reasonable starting point for the scoping analysis. The second computer run used a value of $0.010 \mathrm{in}$. in the finite element model for those elements representing the areas of maximum erosion. This value was chosen to enable the investigation of the stress levels when the walls had suffered severe erosion that might lead to a through-wall leak. The $0.010 \mathrm{in}$. minimum wall thickness value was also used for the third computer run. For the third computer run the same minimum thickness elements were used as for runs one and two; however, the total overall areas of erosion were enlarged to simulate greater areas of erosion in the valve walls. Thus, while the minimum thickness value and area remained the same for the third run, the total eroded area was increased by a factor of approximately 2.5 . This also allowed smoother transitions as the thicknesses were "stepped down" through the erosion areas to the minimum value. 


\section{STRESS ANALYSIS RESULTS}

We used the linear static solver option within the I-DEAS computer code to solve the finite element model when subjected to the combined load sets discussed in Appendix C. The load combinations are repeated below for clarity.

$P_{\text {op }}+F_{\text {rat }}+M_{\text {pipe }}$

$P_{\text {pdh }}+F_{\text {seat }}+M_{\text {pipo }}$

$P_{o p}+F_{\text {reat }}+M_{\text {pipo }}+M_{c o x}$

$P_{o p}+F_{\text {seat }}+M_{p \text { pec }}+M_{o s e}$

$P_{\text {pdh }}+F_{\text {reat }}+M_{\text {pipo }}+M_{\text {oxx }}$

$P_{p d h}+F_{\text {seat }}+M_{p \text { pie }}+M_{o c z}$

where

$$
\begin{aligned}
& \mathrm{P}_{\mathrm{op}} \quad=\text { normal operating pressure (psig) } \\
& \mathrm{F}_{\mathrm{keat}}=\text { valve plug seating force }(\mathrm{lb}) \\
& \mathrm{M}_{\mathrm{oxx}}=\text { operator seismic moment about model global } \mathrm{x} \text { axis (in.-lb) } \\
& \mathrm{M}_{\alpha z z}=\text { operator seismic moment about model global } \mathrm{z} \text { axis (in.-lb) } \\
& \mathrm{M}_{\text {pipo }} \text { = piping system moments at the valve weld ends (in.-lb) } \\
& \mathrm{P}_{\mathrm{pdh}} \quad=\text { pump dead head pressure (psig). }
\end{aligned}
$$

When the calculations were completed, we used the post processing functions within I-DEAS to review the results. Figure D-1 shows a representative color stress contour plot of the eroded bonnet area of the valve. The results shown in Figure D-1 are from the third computer run. We reviewed plots such as this for a variety of stress components and locations on the valve.

The post processing options within the I-DEAS computer code offer the capability to calculate and display a variety of stresses such as principle stresses, maximum shear stress, and Von Mises stress. Depending on the element type being used, results can also be plotted at different surface locations through the element thicknesses. We chose the Von Mises stresses as the values for comparison because research has shown that these stress results will provide a highly accurate indication of material behavior under static loading. We then compared the Von Mises stresses to the material yield strength to predict the onset of nonlinear response. The analytical results for the three computer runs are included in Tables $\mathrm{D}-1, \mathrm{D}-2$, and $\mathrm{D}-3$. 


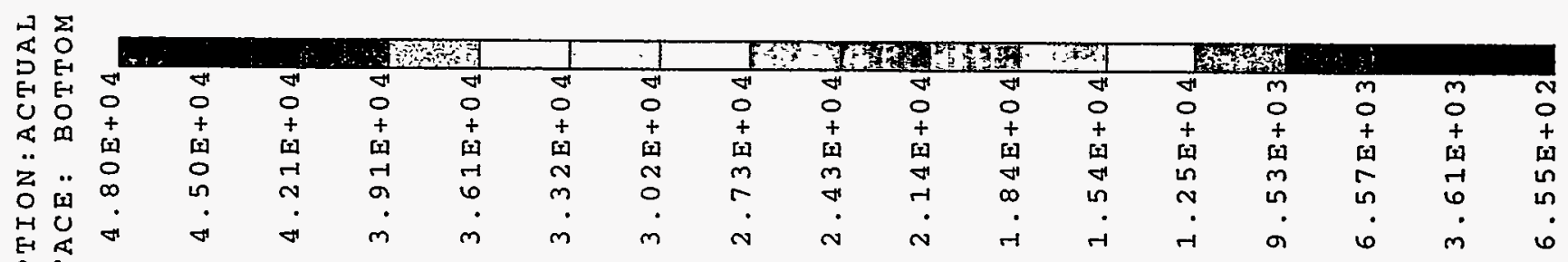

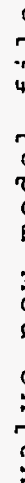

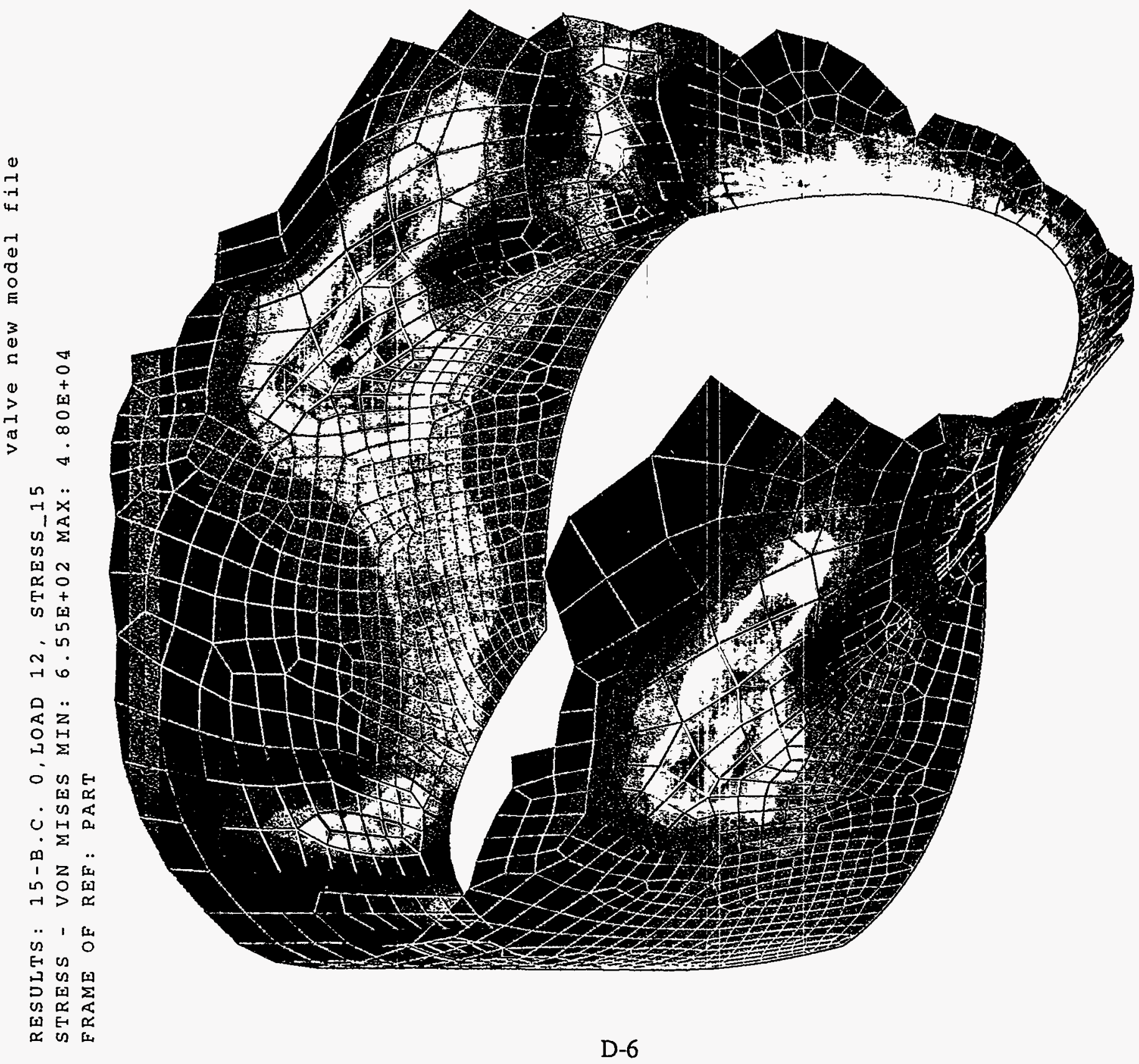

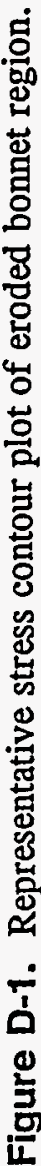


Table D-1. Maximum stress results with $t_{\min }=0.10$ in.

\section{Calculated Von Mises stresses}

(ksi)

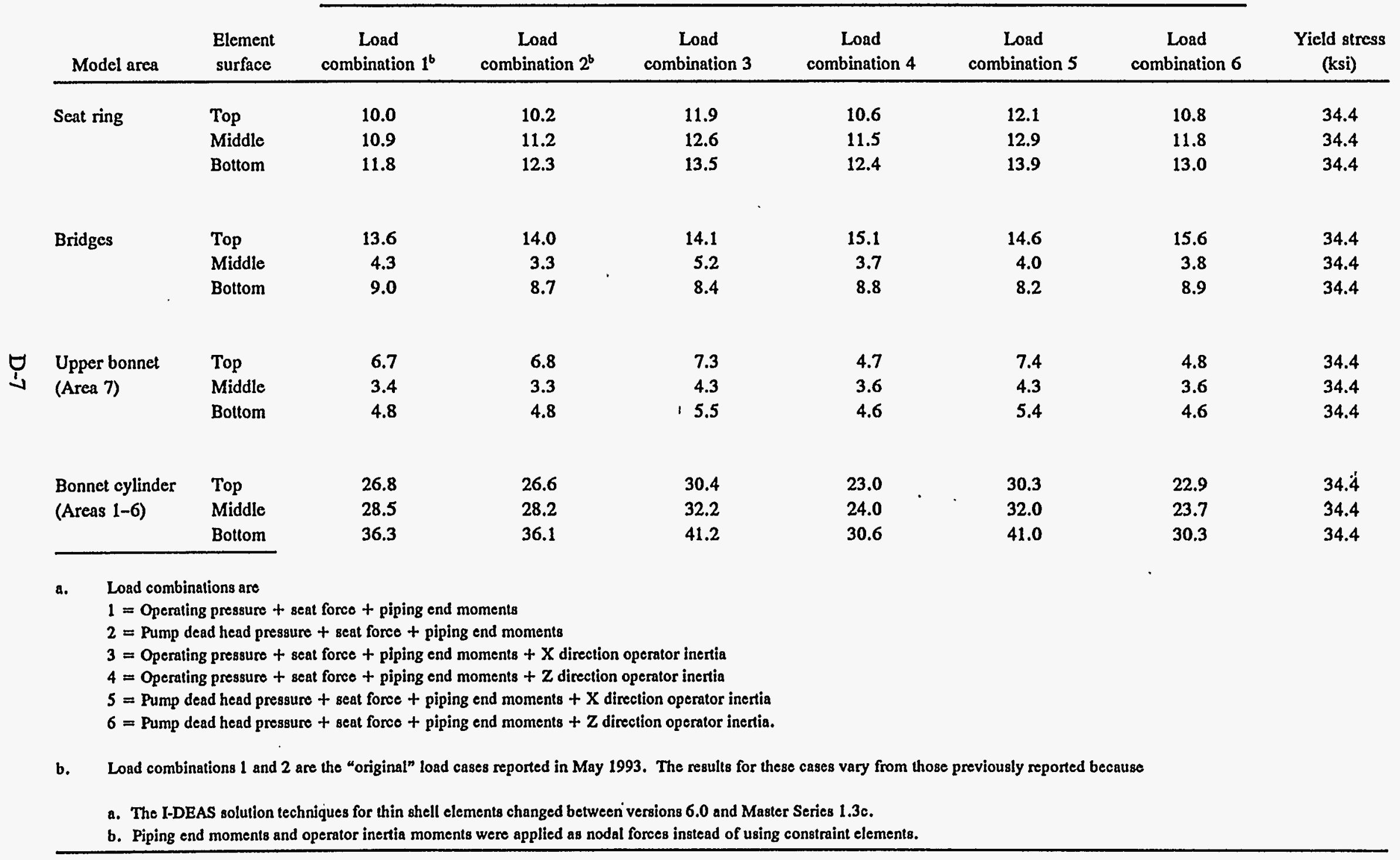


Table D-2. Maximum stress results with $t_{\min }=0.010$ in.

Calculated Von Mises stresses ${ }^{2} \quad$,

(ksi)

\begin{tabular}{|c|c|c|c|c|c|c|c|c|}
\hline Model area & $\begin{array}{l}\text { Element } \\
\text { surface }\end{array}$ & $\begin{array}{c}\text { Load } \\
\text { combination } 1^{b}\end{array}$ & $\begin{array}{c}\text { Load } \\
\text { combination } 2^{b}\end{array}$ & $\begin{array}{c}\text { Load } \\
\text { combination 3. }\end{array}$ & $\begin{array}{c}\text { Load } \\
\text { combination } 4\end{array}$ & $\begin{array}{c}\text { Load } \\
\text { combination } 5\end{array}$ & $\begin{array}{c}\text { Load } \\
\text { combination } 6\end{array}$ & $\begin{array}{l}\text { Yield stress } \\
\text { (ksi) }\end{array}$ \\
\hline \multirow[t]{2}{*}{ Seat ring } & Top & 10.0 & 10.2 & 11.9 & 10.0 & 12.1 & 10.8 & 34.4 \\
\hline & Bottom & 11.8 & 12.3 & 13.5 & 11.8 & 14.0 & 13.0 & 34.4 \\
\hline \multirow[t]{2}{*}{ Bridges } & Top & 13.7 & 14.2 & 14.1 & 13.7 & 14.6 & 15.8 & $34 . \dot{4}$ \\
\hline & Middle & 4.3 & 3.4 & 5.2 & 4.3 & 4.1 & 3.9 & 34.4 \\
\hline Upper bonnet & Top & 6.7 & 6.8 & 7.4 & 6.7 & 7.4 & 4.8 & 34.4 \\
\hline \multirow{2}{*}{ (Area 7) } & Middle & 3.4 & 3.3 & 4.3 & 3.9 & 4.3 & 3.6 & 34.4 \\
\hline & Bottom & 4.8 & 4.8 & 5.4 & 4.8 & 5.4 & 4.5 & 34.4 \\
\hline \multirow{2}{*}{$\begin{array}{l}\text { Bonnet cylinder } \\
\text { (Areas 1-6) }\end{array}$} & Top & 33.0 & 32.9 & 38.9 & 33.0 & 38.8 & 29.0 & 34.4 \\
\hline & Middle & 34.9 & 34.7 & 39.6 & 34.9 & 39.5 & 28.8 & 34.4 \\
\hline
\end{tabular}

a. Load combinations are

1 = Operating pressure + seat force + piping end moments

$2=$ Pump dead head pressure + seat force + piping end moments

$3=$ Operating pressure + seat force + piping end moments $+X$ direction operator inertia

$4=$ Operating pressure + seat force + piping end moments $+Z$ direction operator inertia

$5=$ Pump dead head pressure + seat force + piping end moments $+X$ direction operator inertia

$6=$ Pump dead head pressure + seat force + piping end moments $+Z$ direction operator inertia.

b. Load combinations 1 and 2 are the "original" load cases reported in May 1993. The results for these cases vary from those previously reported because

a. The I-DEAS solution techniques for thin shell elements changed between versions 6.0 and Master Series $1.3 c$.

b. Piping end moments and operator inertia moments were applied as nodal forces instead of using constraint elements. 
Table D-3. Maximum stress results with increased erosion area (third computer run).

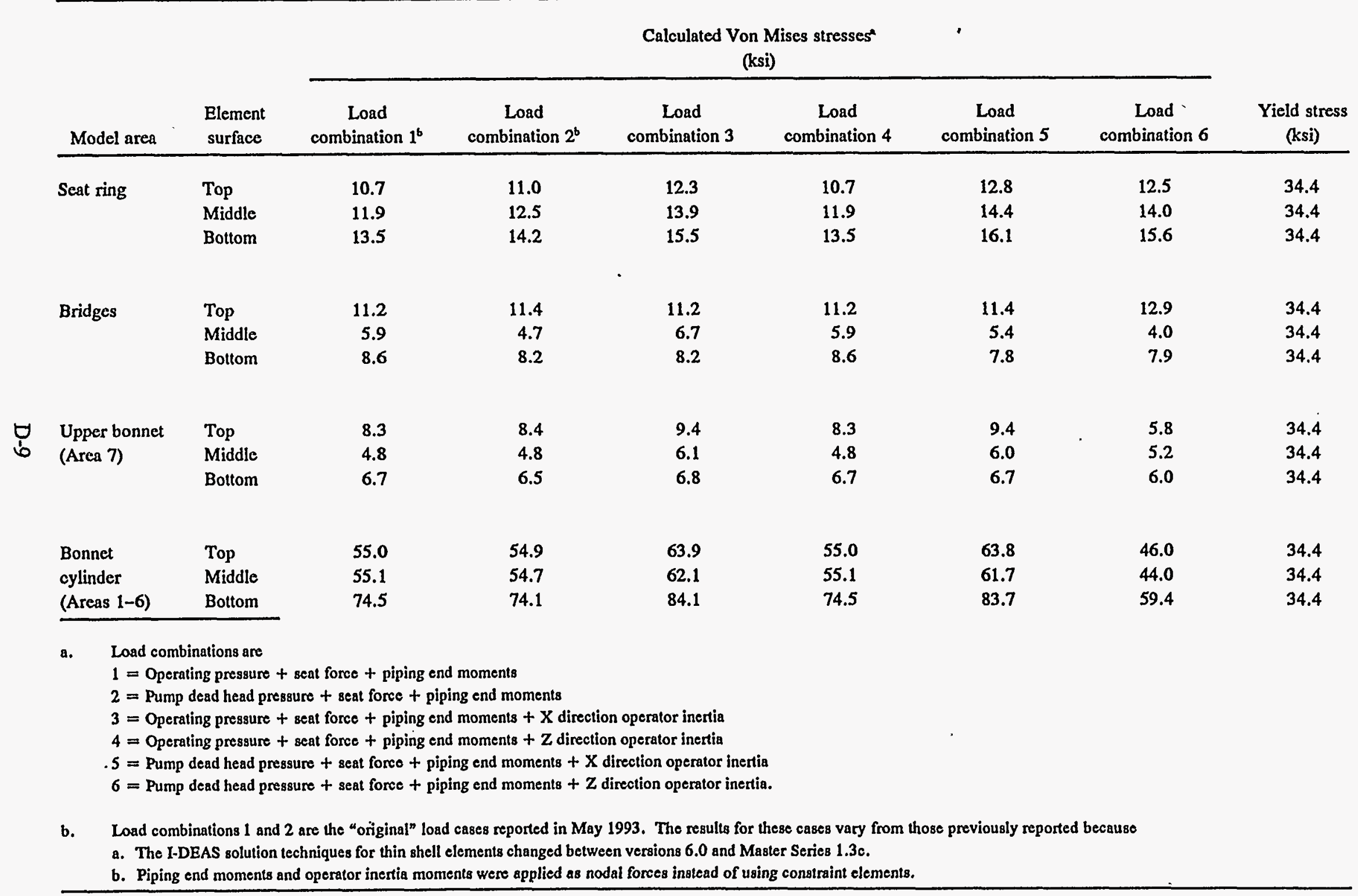

